\title{
From an empty to a full world: a nova natureza da escassez e suas implicações*
}

\author{
Daniel Caixeta Andrade ** \\ Ademar Ribeiro Romeiro *** \\ Marcelo Silva Simões ${ }^{* * * *}$
}

\begin{abstract}
The mainstream vision of the economy is based on a number of assumptions that were created during a period when the world was still relatively empty of humans and their infrastructure (Costanza, 2009, p. 20).

The global economy is now so large that society can no longer safely pretend it operates within a limitless ecosystem. Developing an economy that can be sustained within the finite biosphere requires new ways of thinking (Daly, 2005, p. 100).
\end{abstract}

\section{Resumo}

Este trabalho tem como objetivo principal discutir uma nova representação econômica da natureza da escassez dos recursos representada pela passagem de um empty world para um full world no qual o capital natural é o recurso escasso e limitante do desenvolvimento econômico. Acrescenta-se, ainda, a esta análise, uma avaliação do papel do capital natural enquanto fornecedor de serviços ecossistêmicos úteis ao bem-estar humano. À luz desta nova interpretação sobre a escassez, são discutidas as implicações que este fato encerra para as ciências econômicas em termos da necessidade de em um novo modelo de desenvolvimento, aqui chamado de full world economics ou green consensus, cujo objetivo principal é a preservação e alocação eficiente do capital natural. Acredita-se que esta nova interpretação a respeito da natureza da escassez traga implicações não negligenciáveis tanto para a redefinição dos propósitos de política econômica quanto para a definição de sustentabilidade nas ciências econômicas.

Palavras-chave: Escassez; Capital natural; Empty world; Full world; Full world economics.

\section{Abstract \\ From an empty to a full world: the new nature of scarcity and its implications}

This paper is aimed at discussing a new economic representation for the nature of resources scarcity represented by the passage of an empty world to a full world where natural capital is the scarce and limiting factor of economic development. It is also considered an evaluation of the role of natural

${ }^{*}$ Trabalho recebido em 14 de julho de 2009 e aprovado em 25 de agosto de 2011.

** Professor Adjunto do Instituto de Economia da Universidade Federal de Uberlândia, MG, Brasil. E-mail: caixetaandrade@ie.ufu.br.

${ }^{* * *}$ Professor Titular do Instituto de Economia da Universidade Estadual de Campinas, SP, Brasil. E-mail: ademar@eco.unicamp.br.

***** Mestrando em Economia pelo Instituto de Economia da Universidade Federal de Uberlândia, MG, Brasil. E-mail: mss_1423@hotmail.com. 
capital as a provider of useful ecosystem services to human welfare. In addition, it is pointed out the implications that this fact holds for the economic science in terms of the need for a new development model referred to as full world economics or green consensus, whose main objective would be the preservation and efficient allocation of natural capital. It is argued that this new interpretation of the nature of scarcity has relevant implications either for redefining the purposes of economic policy and for the definition of sustainability in economics.

Keywords: Scarcity; Natural capital; Empty world; Full world; Full world economics.

JEL Q570.

\section{Introdução}

Atualmente, a sociedade humana enfrenta uma série de crises interconectadas que ameaçam a sustentabilidade do regime socioeconômico-ecológico vigente. Exemplos variam desde a mais recente crise econômica, cujas raízes estão na excessiva desregulação do mercado financeiro, passando pelas mudanças climáticas, pelo iminente declínio da produção de recursos naturais essenciais e não renováveis, e pela perda da diversidade biológica, que comprometem a capacidade de o capital natural ${ }^{1}$ prover seus serviços de suporte à vida no planeta.

Em novembro de 1992, um influente e numeroso grupo de cientistas incluindo a maioria dos laureados com o Prêmio Nobel - emitiu um alerta sobre a premência de mudanças na maneira como o ser humano se relaciona com o meio ambiente. Como diz a nota,

human beings and the natural world are on a collision course. Human activities inflict harsh and often irreversible damage on the environment and on critical resources. If not checked, many of our current practices put at serious risk the future that we wish for human society and the plant and animal kingdoms, and may so alter the living world that it will be unable to sustain life in the manner that we know. Fundamental changes are urgent if we are to avoid the collision our present course will bring about (UCS, 1992).

A atualidade desta mensagem é comprovada pela publicação, em outubro de 2008, de um número especial da revista americana New Scientist com o sugestivo título de "The folly of growth: how to stop the economy killing the planet" (New Scientist, 2008). Aí também são feitas previsões pessimistas sobre o futuro da sociedade humana vis-à-vis a contínua destruição do meio natural. Ali se encontram explicitadas as preocupações de vários cientistas sobre a incompatibilidade do atual

(1) O capital natural pode ser considerado como o estoque de recursos naturais existentes que gera um fluxo de serviços tangíveis e intangíveis, direta e indiretamente úteis aos seres humanos, conhecido como renda natural (Costanza; Daly, 1992). Além do capital natural, tem-se, ainda, o capital humano, que é o trabalho físico e humano, e o conhecimento armazenado pela humanidade, o capital manufaturado, que inclui todas as máquinas/equipamentos e toda a infraestrutura do sistema econômico, e o capital social, que se refere à teia de relações interpessoais, bem como às regras, normas e arranjos institucionais criados pelo homem (Costanza, 2000). 
modus operandi do sistema econômico com a manutenção da resiliência do capital natural global ${ }^{2}$.

Do ponto de vista da problemática ambiental, a interconectividade e a interdependência entre as várias populações, proporcionadas pelo fenômeno da globalização, fazem com que uma eventual ruptura repentina no funcionamento do ecossistema global desestabilize o atual regime socioeconômico-ecológico, entendendo-se, este, como o conjunto de normas e regras sociais e econômicas dentro de seu contexto ecológico mais amplo (Costanza et al., 2000).

Essas publicações, entre outras (Daly, 2005; Woodward; Simms, 2006; Jackson, 2009a), sugerem a necessidade de que seja repensada a forma como a humanidade vem se relacionando com o seu meio e, no caso específico que se pretende aludir neste artigo, a forma como as ciências econômicas representam a problemática da escassez dos recursos. Tomando-se as duas epígrafes e a citação acima, afirma-se que a natureza da escassez metamorfoseou-se ao longo do tempo devido, principalmente, ao elevado e crescente ritmo de aumento da escala do sistema econômico. A partir daí, a pergunta primordial que pode ser feita é sobre o significado desta "nova escassez" em termos de ênfase de política econômica.

Ainda que não hegemônica, esta nova interpretação sobre o problema da escassez de recursos impõe-se como um desafio para o instrumental analítico e metodológico das ciências econômicas. Uma vez comprometida com o contínuo aumento do bem-estar e qualidade de vida humana, a análise econômica deveria envidar esforços no sentido de criar pistas teóricas e práticas que evitem e/ou revertam a atual trajetória de contínua degradação das condições mínimas de vida na Terra.

Entretanto, considera-se aqui que, inicialmente, seria necessário que se incorporasse essa nova visão interpretativa da problemática da escassez e que, a partir daí, se discutissem novas estratégias, visando à preservação e alocação eficiente dos recursos que ora passam a ser considerados escassos.

Esta temática de análise é trabalhada por meio das ideias de empty world e full world, desenvolvidas principalmente por Herman Daly e Robert Costanza, que utilizam estas expressões como marco inicial para uma discussão que inevitavelmente

(2) Resiliência pode ser entendida como a habilidade de os ecossistemas retornarem ao seu estado natural após um evento de perturbação natural ou não natural, sendo que, quanto menor o período de recuperação, maior é a resiliência de determinado ecossistema. Pode também ser definida como a medida da magnitude dos distúrbios que podem ser absorvidos por um ecossistema sem que o mesmo mude seu patamar de equilíbrio estável. As atividades econômicas apenas são sustentáveis quando os ecossistemas que as alicerçam são resilientes (Arrow et al., 1995). 
será incorporada ao debate econômico ${ }^{3}$. Partindo-se de uma das definições mais comuns de economia - que sustenta tratar-se da ciência que lida com a escassez dos recursos diante de necessidades ilimitadas ${ }^{4}$-, considera-se que o primeiro passo para se enfrentar a crise mais ampla do atual regime socioeconômico-ecológico seria uma reavaliação dos recursos escassos que deveriam ser objeto da análise econômica, bem como de suas características e os meios pelos quais poderiam ser alocados e preservados.

Neste sentido, os objetivos deste trabalho são: em primeiro lugar, apresentar uma nova interpretação sobre a problemática da escassez de recursos, representada pela passagem de uma visão chamada por Daly (2003, 2005) e Costanza (2008) de empty world para uma de full world e pela consideração do capital natural como provedor de benefícios diretos e indiretos ao ser humano e, em segundo lugar, analisar as implicações colocadas por esta nova transição em termos de política econômica.

Argumenta-se que o atual "mundo cheio", no qual o capital natural é fator escasso e limitante do desenvolvimento econômico, requer a mudança de enfoque da política econômica, privilegiando-se, ao mesmo tempo, as premissas econômicoecológicas de escala ótima, justiça distributiva e eficiência econômica como meios para se compatibilizar desenvolvimento econômico e preservação das condições de vida para as gerações atuais e futuras.

Para que sejam alcançados estes objetivos, o artigo é estruturado em quatro seções, além desta introdução e considerações finais. Na primeira seção, discutese, brevemente, o tratamento da escassez de recursos na forma como é apresentado pela análise convencional. Historicamente, o debate em torno da questão sobre se a escassez de recursos naturais seria ou não um impedimento ao contínuo crescimento econômico deu margem ao surgimento de visões pessimistas e otimistas sobre o futuro das atividades econômicas. Contudo, algumas premissas adotadas, como a de substituibilidade entre capital natural e manufaturado, fizeram com que, tradicionalmente, a escassez do capital natural não fosse vista como um problema relevante na análise econômica, relegando, em última instância, o objetivo de sua preservação a um segundo plano.

3 Um bom exemplo de incorporação crescente dessa temática no debate econômico pode ser encontrado em Arnt (2010), por meio do qual importantes economistas brasileiros, tanto do mainstream econômico como de correntes mais críticas, apresentam suas percepções sobre a sustentabilidade e possibilidades de desenvolvimento econômico no atual cenário de degradação do capital natural. Não obstante as divergências, as opiniões ali expressas permitem extrair a interpretação de que o debate ambiental consolidou-se como obrigatório na análise econômica, muito embora se possa considerar que o tratamento dado à questão seja frequentemente reducionista e/ ou insatisfatório.

(8) Esta definição contemporânea das ciências econômicas é atribuída ao economista britânico Lionel Charles Robbins (Barão Robbins, 1898-1984). 
A segunda seção traz uma análise sobre os argumentos que levam à interpretação de que se pode apontar para a emergência do fenômeno de uma "nova escassez". A consideração conjunta do aumento contínuo e elevado da escala do sistema econômico e do capital natural como fundo de serviços suporta a tese de um novo padrão de escassez que pode ser visto como um problema complexo e multifacetado dadas as questões de irreversibilidades, não linearidades e interdependências dos processos ecológicos que passam a ser incorporadas na análise.

A terceira seção discute, preliminarmente, um novo modelo de análise econômica que considera explicitamente os desafios colocados pela emergência do full world. Este novo modelo, que pode ser chamado de full world economics ou green consensus, tem como pressuposto básico a preservação e alocação eficiente do capital natural numa perspectiva de que este deve ser visto como um portfolio de ativos tangíveis e intangíveis para a sociedade, além de incorporar explicitamente a visão pré-analítica de que o sistema econômico está contido em um sistema maior que o sustenta.

Por fim, à guisa de conclusão, são tecidos alguns comentários sobre o significado das considerações feitas ao longo do trabalho. Em primeiro lugar, a nova interpretação sobre a natureza da escassez sugerida recupera o verdadeiro sentido de sustentabilidade dentro das ciências econômicas. Em segundo lugar, depreende-se, tendo em vista as reflexões realizadas e as perspectivas de crescimento econômico para o mundo em desenvolvimento durante a primeira metade do século XXI, que o próprio conceito de prosperidade humana deve ser repensado. Por fim, sugere-se que, em face das especificidades do capital natural enquanto fator escasso, políticas devem ser elaboradas a partir do tripé sustentabilidade ecológica, equidade social e eficiência econômica.

\section{Ciência econômica, escassez e capital natural}

A grande maioria dos livros-texto de Economia traz sua definição como a ciência da escassez, no sentido de alocar recursos escassos entre objetivos desejáveis e frequentemente conflitantes entre si. Esta alocação deve ser eficiente e servir ao objetivo supremo de crescimento econômico, entendendo-o como o aumento de bens e serviços disponíveis para a satisfação dos agentes econômicos.

Como afirma Gillespie (2007, p. 4), "we would like to do and have everything, but because resources are scarce we must make choices". Em outras palavras, a condição de escassez dos recursos impõe limites à consecução de todos os objetivos individuais e/ou coletivos, o que pressupõe a necessidade de se incorrer em sacrifícios, impondo, assim, um custo implícito (custo de oportunidade) a todas as atividades humanas, sejam elas econômicas ou não. 
O Dicionário Aurélio da Língua Portuguesa define "escasso" como aquilo "que há pouco, raro, parco", e "finito" como aquilo "que tem fim, transitório, contingente, limitado". O Longman Dictionary of Contemporary English afirma que "if something is scarce, there is not much available of it". Adicionalmente, este último dicionário também define "finito" como alguma coisa como "having an end or a limit".

Aparentemente frívola, a análise destes dois adjetivos pode revelar um ponto de vista muitas vezes considerado tácito, mas não colocado em prática. Quando se afirma, por exemplo, que os recursos financeiros de uma economia são escassos, a ideia que se quer transmitir é que esta economia dispõe de recursos financeiros finitos. Esta qualificação requer, portanto, que os recursos não sejam apenas manejados eficientemente, de maneira que se obtenha cada vez mais, utilizando-se de menores quantidades, mas também que o sejam de maneira tal que o seu estoque de origem não seja completamente consumido ${ }^{5}$.

Quando o estoque de recursos é renovável, quer seja pelas características intrínsecas dos recursos, ou por meio de adições ao seu estoque, é prudente que sua taxa de utilização não exceda sua taxa de renovabilidade. Do contrário, o mesmo estoque, antes considerado abundante e infinito devido à sua capacidade de renovação, pode se tornar escasso e finito. Já quando o estoque de recursos é não renovável, é necessário que haja um consenso de que é imperativo encontrar soluções que impeçam a sua completa depleção. Ou seja, este último tipo de estoque requer a adoção de práticas que garantam a sua sustentabilidade ao longo do tempo.

Assim, questões sobre alocação e conservação/preservação dos recursos são dois aspectos do mesmo problema: a escassez e finitude dos recursos. Entretanto, as discussões sobre o objetivo das ciências econômicas enfocam, majoritariamente, apenas o problema da alocação, prescindindo do debate sobre a preservação. Aparentemente, este fato se justifica por ser conflitante discutir a conservação dos recursos vis-à-vis a inquestionável necessidade de sua utilização. Ademais, o modo pelo qual a atual sociedade capitalista se estruturou não é favorável à adoção de padrões coercivos ao objetivo máximo de crescimento econômico.

Nesta perspectiva, é preciso que se inclua explicitamente o objetivo de preservação dos recursos nas definições das ciências econômicas. Isso porque

(5) É importante dizer que, formalmente, os adjetivos "escasso" e "finito" não podem ser considerados sinônimos, já que um recurso escasso (abundante) tecnicamente pode ser infinito (finito) ao mesmo tempo. No entanto, semanticamente, o atributo de escassez quase sempre conduz à ideia de caráter finito e transitório de um recurso. Isto porque é difícil conceber um recurso que possua, simultaneamente, os atributos de escasso e infinito. Neste sentido, a argumentação aqui colocada é que os recursos escassos, objetos da análise econômica, são, em sua maior parte, também finitos, o que pressupõe a necessidade de preservá-los. Naturalmente, há que se considerar a capacidade de renovação de alguns recursos mas, a depender das taxas de utilização, esta renovabilidade será comprometida, e considerações sobre finitude são aplicáveis também a estes recursos. 
a alocação eficiente dos recursos, implicitamente atribuída ao livre mercado, não necessariamente conduz à preservação dos mesmos. Como afirma Barnes (2006, p. 49) “... private corporations, operating in unconstrained markets, can allocate resources efficiently but can't preserve them. The latter task requires setting aside some supplies for future generations - something neither markets nor corporations, when left to their own devices, will do." (grifos no original).

Além de alocar e preservar os recursos, uma definição razoável das ciências econômicas requereria que fossem claramente determinados os objetivos a serem alcançados (bem como o modo pelo qual estes devem ser perseguidos), com quais tipos de recursos se está tratando, quais são suas características e como (e por quem) deve ser feita sua alocação e preservação. No que se refere aos objetivos perseguidos, é consenso que o aumento do bem-estar geral e incremento na qualidade de vida têm sido, explícita ou implicitamente, os principais objetivos de política para os indivíduos, comunidades e nações.

Dentro da visão econômica mainstream, o crescimento econômico ilimitado é tido como o principal veículo de obtenção dos objetivos da sociedade e o fim último da política econômica (growthmania). Todavia, existem evidências abundantes de que maior crescimento material não conduz necessariamente a um aumento do bemestar e da felicidade humana (Easterlin, 2003). Este fato pressupõe a necessidade de reavaliação sobre os meios possíveis para uma melhoria qualitativa das condições de vida não baseada exclusivamente no crescimento econômico ${ }^{6}$.

A característica de escassez atribuída ao capital natural, que deve ser considerado tanto do ponto de vista de um de conjunto de ativos tangíveis (recursos naturais) como em sua dimensão de fornecedor de benefícios úteis para o bem-estar humano - os chamados serviços ecossistêmicos (Daily, 1997) ${ }^{7}$-, foi historicamente alvo das análises de economistas preocupados com a possibilidade de que essa escassez viesse a se configurar um obstáculo ao crescimento econômico. O economista clássico Thomas Malthus, a quem é atribuída a famosa relação entre crescimento da população e oferta de alimentos, pode ser considerado o marco inicial das preocupações econômicas com a escassez dos recursos naturais, muito embora preocupações de cunho filosófico sobre a apropriação humana dos recursos da natureza venham de longa data.

(6) A discussão sobre a profunda aderência da sociedade atual ao crescimento econômico e sua suposta correspondência direta com o aumento do bem-estar das populações, bem como suas implicações sociais, econômicas e ambientais, foge ao escopo deste trabalho, embora se admita a importância deste tema para o debate sobre os modelos alternativos de regimes socieconômico-ecológicos. Para maiores detalhes sobre esta temática, ver, principalmente, Victor (2008), Costanza et al. (2008), Beddoe et al. (2009) e Jackson (2009b).

(7) É importante ressaltar que o debate clássico sobre escassez focava apenas a dimensão de fornecedor de recursos naturais do capital natural, negligenciando sua dimensão fundo de serviços. A incorporação desta última nas análises legitima, em parte, a nova interpretação da natureza da escassez - objeto principal deste trabalho -, que será melhor discutida nas próximas seções. 
Dentro do debate clássico sobre escassez e crescimento econômico, conclusões estilizadas são encontradas em Barnett e Morse (1963) e Barnett (1979). Através de análises quantitativas e diagramáticas, estes autores procuraram mostrar que, em última instância, a escassez do capital natural, visto majoritariamente como um portfolio de recursos naturais tangíveis, não seria um óbice ao crescimento econômico. Os mecanismos que sustentam tal ilação são mormente ancorados no aparato mercadológico: à medida que os recursos se tornam escassos, seus preços se elevam e surgem incentivos para a obtenção de substitutos aos recursos escassos acompanhados de novas tecnologias poupadoras de recursos naturais (backstop technologies $)^{8}$. De maneira sintética, este é o fulcro da visão convencional sobre escassez, o que reforça a tese de que, neste diapasão, o objetivo de preservação não é relevante, já que, em última instância, pode-se neutralizar os efeitos das perdas do capital natural.

Existem alguns aspectos interessantes sobre as premissas implícitas no esquema analítico convencional responsáveis por tornar a preservação do capital natural em um tema não relevante ao hardcore das ciências econômicas. Embora sempre houvesse o conhecimento da natureza escassa e finita de alguns recursos naturais, a questão básica para a qual se deve buscar uma compreensão mais aprofundada passa a ser o descolamento dos objetivos de alocação eficiente e preservação dos recursos. Enquanto o primeiro foi eleito como o objetivo único das ciências econômicas, o segundo assumiu um papel secundário ou mesmo inexistente, mesmo sendo senso comum que a alocação pode ser totalmente inviabilizada pela inexistência do próprio capital natural. Diante disso, a forma de se expressar, de maneira lacônica, o argumento que se pretende construir é através da pergunta: por que, a despeito do conhecimento sobre sua escassez, a preservação do capital natural não mereceu o devido tratamento dentro da teoria econômica convencional?

As respostas teóricas tradicionais a essa pergunta foram sucintamente descritas acima. Em primeiro lugar, as soluções recorrentemente buscadas no avanço tecnológico sempre tiveram proeminência em discursos que enfocam essa problemática. Essa crença encontra-se explicitada nas palavras de Simon (1995), que afirma que "technology exists now to produce in virtually inexhaustible quantities just about all the products made by nature (...) We have in our hands now-actually, in our libraries - the technology to feed, clothe, and supply energy to an ever-growing population for the next 7 billion years”. O mesmo eixo de argumentação também

(8) É justo afirmar que, concomitante às visões otimistas, há vários exemplos de análises que ressaltaram o caráter contraditório entre crescimento econômico e escassez do capital natural. Meadows et al. (1972) apontam para um cenário de impossibilidade de perpetuação do crescimento econômico devido à exaustão dos recursos ambientais por ele acarretada, levantando, assim, a proposta de um crescimento econômico "zero". Nordhaus (1974) resgata a metáfora da economia do cowboy e da economia da espaçonave (Boulding, 1966), e lança um olhar cético sobre as possibilidades de o progresso tecnológico relativizar os constrangimentos trazidos pela escassez do capital natural sobre o crescimento econômico. 
está em Solow (1974), para quem as tecnologias natural-resource-savings podem "libertar" o crescimento econômico dos óbices trazidos pela escassez e exaustão dos recursos. Assim, "the world can, in effect, get along without natural resources, so exhaustion is just an event not a catastrophe" (p. 11) ${ }^{9}$.

Em segundo lugar, a hipótese implícita de substituibilidade entre capital produzido pelo homem e capital natural é crucial, uma vez que, na sua ausência, são infrutíferos os esforços para a criação de substitutos aos recursos naturais. Num cenário de avanço tecnológico ininterrupto e possibilidade de substituição entre os dois tipos de capital (natural e manufaturado), é plenamente justificável a não preocupação com a trajetória de utilização do capital natural. O problema é que, mesmo que se considerem como dinâmicas e contínuas as atividades de inovação, é forçoso admitir que o segundo elo dessa racionalidade é frágil e facilmente contestado, já que possui pouco suporte lógico e prático. Se o capital construído pelo homem fosse um substituto perfeito do capital natural, este também seria um substituto perfeito para o primeiro. Se esse fosse o caso, não haveria necessidade de produção de capital construído pelo homem, dado que o capital natural já está disponível (Costanza; Daly, 1992).

Em terceiro lugar, a interpretação de que a escassez do capital natural não impõe riscos ao crescimento econômico decorre fundamentalmente da excessiva ênfase na visão de que aquele é constituído apenas por um conjunto de ativos naturais tangíveis e na desconsideração da complexidade dos processos ecológicos, da não linearidade das relações entre os componentes do capital natural e da possibilidade de perdas irreversíveis e potencialmente catastróficas. A ausência de uma compreensão holística do papel do capital natural enquanto suporte das atividades humanas reduz a análise a um problema de degradação de estoque. Este fato relaciona-se à inspiração mecanicista que fundamenta epistemologicamente a teoria econômica convencional, que a permite prescindir da complexidade envolvida em fenômenos não reversíveis (Georgescu-Roegen, 1971). Numa visão econômico-ecológica mais ampla, a depleção do capital natural deve ser vista como um processo duplamente maléfico para a sociedade humana: a perda de fluxos materiais tangíveis (recursos naturais) e a perda - potencialmente irreversível - de elementos que geram fluxos de benefícios intangíveis (serviços ecossistêmicos) ${ }^{10}$.

(9) É bem verdade que, recentemente, Robert Solow aparentemente reviu sua posição com relação a esse debate. Duas de suas afirmações recentes - "there is no reason at all why capitalism could not survive without slow or even no growth. I think it is perfectly possible that economic growth cannot go on at it current rate forever. " $\mathrm{e}$ "it is possible that U.S. and Europe will find that, as the decades go by, either continued growth will be too destructive to the environment and they are too dependent on scarce natural resources, or they would rather use increasing productivity in the form of leisure ... There is nothing intrinsic in the system that says it cannot exist happily in a stationary state." (Stoll, 2008) - parecem atestar sua nova concepção de que o capital natural pode impor limites ao crescimento econômico.

(10) Para maiores detalhes sobre a importância dos serviços ecossistêmicos para o sistema econômico e bem-estar humano, ver Andrade e Romeiro (2009a). 
Desconsiderar o papel do capital natural enquanto provedor de serviços fundamentais ao bem-estar humano significa não reconhecer a interdependência entre estrutura e funções do capital natural e sua resiliência, além de incorrer em análises reducionistas. Ao se incorporar na análise a concepção de que o capital natural é um fundo de serviços essenciais à manutenção das condições mínimas de vida e considerações sobre a natureza complexa dos fenômenos ecológicos, ampliase a problemática da escassez do capital natural enquanto tema relevante para a discussão sobre a sustentabilidade das atividades econômicas.

\section{From an empty to a full world: o capital natural como fator escasso}

Quanto à definição dos recursos que precisam ser alocados e preservados, é necessário, em primeiro lugar, observar a evolução da natureza da escassez de recursos, uma vez que esta não é estável devido à dinâmica do próprio sistema econômico. A utilização excessiva de recursos, independentemente se seus estoques de origem são ou não renováveis, pode acarretar seu escasseamento ou a sua completa extinção. Ademais, alguns recursos possuem características peculiares que os conduzem naturalmente a uma situação de superexploração, como é o caso dos recursos de acesso livre, com atributos de bens públicos (Hardin, 1968).

A crença no crescimento econômico contínuo propiciou um aumento sem precedentes da escala das atividades econômicas e de seus efeitos adversos sobre o ecossistema global, o que, de acordo com McNeill (2000), pode ser considerado como o que há de efetivamente "novo sob o Sol". Esta expansão vem, desde a Revolução Industrial, conduzindo o mundo a uma era na qual o capital natural vem substituindo o capital produzido pelo homem (man-made capital) como fator escasso e limitante ao desenvolvimento econômico (Daly, 1996; Costanza, 2000; Daly; Farley, 2004). Houve, assim, uma alteração significativa na natureza da escassez dos recursos, passando-se de um empty world para um full world.

Conforme já explicitado, as ideias de empty world e full world foram introduzidas por Herman Daly (Daly, 2003, 2005) e Robert Costanza (Costanza, 2008). Segundo estes dois autores, o empty world está relacionado a um período no qual o capital natural era relativamente abundante e o capital produzido era o fator escasso e limitante do desenvolvimento econômico. Neste período, era lícita a preocupação com a acumulação de capital e a desconsideração com as externalidades negativas das atividades humanas dado o tamanho diminuto da escala do sistema econômico. Todavia, o excessivo acúmulo de capital produzido pelo homem e a decorrente degradação do meio natural culminaram no chamado full world, no qual se inverte a natureza da escassez de recursos. A causa primária de tal inversão pode ser encontrada na trajetória do sistema capitalista, bem como em suas falhas inerentes e no aumento ininterrupto da escala do sistema econômico. 
Em consonância com as análises de Costanza (2008) e Daly (2003, 2005), Barnes (2006) também aponta para uma mudança na natureza da escassez dos recursos representada pela "atualização" do sistema capitalista de sua "versão 1.0" para sua versão "2.0”. Segundo este último autor, até o ano de 1950, a sociedade humana vivia no que pode ser chamado de "capitalismo da insuficiência" (shortage capitalism), que representava a primeira versão do sistema (Capitalism 1.0). Logo após a Segunda Guerra Mundial, o sistema capitalista foi atualizado e atingiu sua segunda versão (Capitalism 2.0), que pode ser apontada como o "capitalismo do excesso" (surplus capitalism). Nesta última, o poder das corporações foi elevado ao seu grau máximo e o seu grande aríete é a produção de novas demandas e a expansão massiva do crédito.

Entre as principais diferenças destas duas versões, Barnes (2006) chama a atenção para a mudança da natureza da escassez dos recursos: enquanto no "Capitalismo 1.0" os bens econômicos, em geral, eram escassos, e sua produção e acumulação eram justificáveis, no "Capitalismo 2.0" há uma relativa abundância destes bens antes escassos. A nova escassez passa a englobar, entre outros, os ativos comuns provenientes do chamado capital natural, principalmente no que diz respeito à sua capacidade de absorção dos resíduos das atividades econômicas. Este último aspecto se coaduna com a argumentação da seção anterior, pois sugere a consideração do capital natural como provedor de benefícios ao bem-estar humano.

Em meados do século XVIII, o período que se inicia com a Revolução Industrial, cuja característica central é a industrialização e o uso massivo de combustíveis fósseis, marca o fim de uma longa era de estabilidade geológica em que os mecanismos naturais do planeta eram capazes de absorver os impactos endógenos e exógenos sofridos pela ecosfera terrestre. Tal período, conhecido como Holoceno, testemunhou grande parte da trajetória da civilização humana em que o homem passou de caçador, coletor e nômade para estágios de intervenção cada vez mais agressivos ao meio ambiente.

$\mathrm{O}$ início da era industrial sinalizou o alvorecer de um novo período - o Antropoceno -, no qual a estabilidade característica do Holoceno deixou de ser o traço marcante. A centralidade das intervenções antrópicas nos desequilíbrios dos sistemas naturais terrestres e a ameaça à resiliência do capital natural global marcam a nova era (Steffen et al., 2007, Rockström et al., 2009a, Rockström et al., 2009b). Elevaram-se os riscos de perdas irreversíveis e potencialmente catastróficas e tornaram-se cada vez mais claros os sinais de mudanças globais, entendendo-as como alterações biofísicas e socioeconômicas que modificam a estrutura e o modo de funcionamento do sistema terrestre.

A magnitude dos impactos do Antropoceno e seus desdobramentos sobre a capacidade de resiliência do capital natural vêm aumentando enormemente desde 
o fim da Segunda Guerra Mundial. No período que se inicia após 1945, conhecido como a Grande Aceleração, a população mundial duplicou em apenas 50 anos (mais de 6 bilhões no fim do século XX), o sistema econômico mundial aumentou em mais de 15 vezes, o consumo de petróleo tem crescido por um fator de 3,5 desde 1960 e o número de veículos automotores apresenta um crescimento sem precedentes (Steffen et al., 2007). Além disso, entre um terço e metade da superfície terrestre foi transformada pela ação humana; a concentração de dióxido de carbono $\left(\mathrm{CO}_{2}\right)$ na atmosfera atinge níveis cada vez mais preocupantes e um número crescente de espécies corre risco de extinção (Vitousek et al., 1997).

A elevação da escala das atividades humanas tem provocado extensivas e rápidas mudanças no capital natural da Terra. De acordo com o Millennium Ecosystem Assessment (MEA, 2005) ${ }^{11}$, as alterações sofridas pelos ecossistemas do planeta não são comparáveis a nenhum outro período da história humana e, embora tais mudanças tenham contribuído significativamente para ganhos líquidos no desenvolvimento e crescimento econômico, tais ganhos foram alcançados a custos crescentes na forma de degradação de serviços ecossistêmicos.

Embora haja uma crescente adesão à ideia de que a escala do sistema econômico e os padrões de consumo decorrentes do estilo de desenvolvimento em curso são insustentáveis do ponto de vista ecológico, percebe-se que ainda existem sérias lacunas no que diz respeito à mensuração das escalas atuais do sistema econômico, bem como à escala ótima que este deveria assumir. Avaliações biofísicas e econômicas dos impactos humanos sobre os ecossistemas e sua resiliência são condições sine qua non para a elaboração e implementação de políticas que visem ao desenvolvimento sustentável. Mesmo que incertezas e a falta de uma completa compreensão dos processos ecológicos dificultem ou mesmo inviabilizem análises sobre a magnitude da escala humana, é preciso a integração transdisciplinar para a construção de referenciais que elucidem limiares seguros até os quais a atividade econômica pode avançar.

O crescente aumento da escala do sistema econômico é visto, pois, como a principal causa da mudança na natureza da escassez de recursos. Aliado a isso, a compreensão de que o capital natural provê benefícios essenciais à vida reforça a ideia de uma "nova escassez". Se as análises sobre escassez e crescimento econômico focalizavam minerais, alimentos em geral, madeira e combustíveis fósseis, em termos de disponibilidade física, crescente atenção tem sido dada às amenidades do capital natural, tais como estabilização climática, qualidade das

(11) A Avaliação Ecossistêmica do Milênio (2001-2005) foi uma iniciativa das Organizações das Nações Unidas (ONU), sob a liderança do seu então secretário-geral, Kofi Annan, de realização de um estudo envolvendo cientistas de todo o mundo com o objetivo de avaliar as consequências das mudanças nos ecossistemas para o bemestar humano e fornecer bases científicas para a ação necessária ao avanço na conservação e uso sustentável desses sistemas que suportam a vida no planeta. 
águas, capacidade de absorção de resíduos, o papel da diversidade biológica etc., reconhecidas como serviços ecossistêmicos. Para estes novos recursos escassos, todos eles não transacionáveis nos mercados tradicionais, há a impressão geral de que apenas o progresso tecnológico pode não ser suficiente para solucionar os problemas decorrentes de sua degradação, uma vez que estão presentes novos elementos ligados à complexidade dos fenômenos ecológicos (Simpson et al., 2004; Krautkraemer, 2005).

O conceito de capital natural aqui utilizado considera todos os fluxos de benefícios tangíveis e intangíveis provenientes de todos os recursos naturais e que são direta e indiretamente apropriáveis pelo homem, englobando todos os recursos presentes no conjunto dos ecossistemas. Ao adotar este conceito mais amplo, a definição aqui adotada confere ao capital natural um caráter multidimensional no qual dimensões ecológicas, econômicas e socioculturais estão relacionadas e interagem entre si para a promoção do bem-estar humano (Berkes; Folke, 1994).

Considerando o capital natural como o conjunto de ecossistemas existentes no planeta, o entendimento da natureza da "nova escassez" requer o estudo da dinâmica dos ecossistemas e dos mecanismos pelos quais são gerados os serviços ecossistêmicos. O interesse por esses temas é relativamente recente, tendo ganhado importância considerável devido à crescente preocupação sobre as interconexões entre o estado dos ecossistemas, o bem-estar das populações humanas e os impactos negativos que mudanças drásticas nos fluxos de serviços essenciais prestados pelos ecossistemas podem ter sobre o bem-estar das sociedades.

Enquanto sistemas complexos, os ecossistemas apresentam várias características (ou propriedades), como variabilidade, resiliência, sensibilidade, persistência, confiabilidade etc. (Levin, 1998). Entre elas, as propriedades de variabilidade e resiliência apresentam importância crucial para uma análise integrada das interconexões entre ecossistemas, sistema econômico e bem-estar humano (Andrade; Romeiro, 2009).

A variabilidade dos ecossistemas consiste nas mudanças dos estoques e fluxos ao longo do tempo devido, principalmente, a fatores estocásticos, intrínsecos e extrínsecos $1^{12}$. Já a resiliência é fundamental para estabelecer parâmetros de uso sustentável dos ecossistemas, uma vez que estes podem ser manejados, até determinado ponto, sem que haja mudanças substanciais em suas propriedades.

O ponto de mudança de patamar (ou de ruptura) é definido como o limiar de resiliência dos ecossistemas. Os limiares, ou pontos de ruptura (breakpoints), são aqueles pontos limite além dos quais há um dramático e repentino desvio em relação

(12) Para maiores detalhes sobre as características e princípios fundamentais de funcionamento dos ecossistemas, ver Jorgensen (1992). Por eventos intrínsecos entendem-se os mecanismos de autorregulagem dos ecossistemas, e eventos extrínsecos são aqueles oriundos de intervenções externas (antrópicas ou não). 
ao comportamento médio dos ecossistemas (MEA, 2003). A possibilidade de perdas irreversíveis, bem como a ignorância relativa ao funcionamento sistêmico, imprimem elevado grau de incerteza em estudos que utilizam o conceito de ecossistemas como unidade básica de análise (Daly; Farley, 2004), evidenciando a necessidade de adoção de comportamentos precavidos diante de incerteza e riscos (Romeiro, 2002).

Além de se levar em consideração a necessidade de preservação dos recursos e a discussão sobre a nova natureza da escassez (de um empty world para um full world), é preciso ainda que se discuta a natureza dos novos recursos escassos e os meios possíveis para uma gestão eficiente e sustentável dentro deste novo contexto. Enquanto fator escasso, a explicitação da natureza dos componentes do capital natural é importante no sentido de que, apenas a partir de um correto entendimento da dinâmica de cada tipo de recurso, haverá condições de se tomar ações para sua proteção.

Daly e Farley (2004), seguindo divisão originalmente sugerida por Georgescu-Roegen (1971), classificam os componentes do capital natural em recursos estoque-fluxo e recursos fundo-serviço (stock-flow resources e fund-service resources, respectivamente). Recursos estoque-fluxo são aqueles provenientes do capital natural que são incorporados ao produto final. Produzem um fluxo material que pode ser de qualquer magnitude, sendo que o estoque que o gerou pode ser usado a qualquer taxa. A unidade apropriada para mensurar a produção de um recurso estoque-fluxo é a quantidade física de bens que podem ser produzidos, sendo que o fluxo material resultante pode ser estocado para usos futuros. Esta é, basicamente, a vertente utilizada nas interpretações tradicionais sobre a escassez do capital natural.

Os recursos fundo-serviço, por sua vez, são aqueles que não são incorporados ao produto final. Eles produzem serviços a taxas fixas e não podem ser estocados para uso futuro. Ao contrário dos recursos estoque-fluxo, que são completamente "gastos" no processo de produção, os recursos fundo-serviço são apenas depreciados, podendo ser reutilizados em um novo ciclo de produção. A preocupação central é com a capacidade de os recursos fundo-serviço cumprirem o seu propósito. Ao incorporá-los à análise (Andrade; Romeiro, 2011), o estudo da "nova escassez" tornase mais amplo e complexo, uma vez que a degradação de um determinado fluxo de serviço leva à desestabilização de outras funções ecossistêmicas, culminando em novas fontes potenciais de fragilidade e escassez. É neste sentido que se afirma que esta nova natureza da escassez é um problema complexo e multifacetado dada a interdependência das funções ecossistêmicas. Os processos de geração dos serviços ecossistêmicos envolvem intrincadas relações - mormente não lineares e complexas - dentro da estrutura ecossistêmica. Especial ênfase deve ser dada à biodiversidade, que pode ser definida como a variabilidade entre os organismos vivos entre ecossistemas terrestres, marinhos e outros ecossistemas aquáticos, além de todos os processos ecológicos dos quais tais organismos fazem parte (CBD, 1992, artigo 
2). A perda da biodiversidade representa a maior ameaça aos ecossistemas e à sua capacidade de sustentar processos ecológicos básicos que suportam a vida no planeta (Naeem et al., 1999).

Alguns resultados listados pelo relatório The Economics of Ecosystem \& Biodiversity Study (Sukhdev, 2008) apontam que, nos últimos 300 anos, a área global coberta por florestas diminuiu aproximadamente $40 \%$, sendo que, em 25 países, as florestas desapareceram completamente, e, em outros 29 países, sua cobertura original reduziu-se em mais de 90\%. Trata-se de um dado preocupante, uma vez que as florestas são naturalmente grandes reservatórios de biodiversidade e, por conseguinte, grandes provedoras de serviços ecossistêmicos. Outro resultado alarmante é a taxa antropogênica de extinção de espécies que é tida como mil vezes mais rápida que a taxa natural de extinção conduzida pelos ciclos de vida da Terra.

Especialistas em ciências naturais são unânimes em afirmar que ecossistemas mais diversos são ecologicamente mais produtivos e oferecem uma gama maior de fluxos de serviços ecossistêmicos, tais como sequestro de carbono, proteção contra catástrofes naturais etc. (Tilman; Polasky, 2005). A tendência de homogeneização das paisagens a partir de mudanças de uso da terra que privilegiam ecossistemas pobres em diversidade biológica torna ainda mais visível a nova natureza da escassez aqui sugerida. Os serviços ecossistêmicos e a biodiversidade que os suportam são recursos não incorporados nas transações econômicas convencionais, e sua alocação não pode ser feita eficientemente pelos instrumentos de mercado. Além disso, os sinais de escassez via sistema de preços são falhos. Apenas a partir de evidências de sua degradação ou mesmo após a ocorrência de potenciais catástrofes em função da perda total de alguns fluxos de serviços ecossistêmicos ou extinção de espécies é que se pode avaliar o seu grau de escasseamento e as consequências daí decorrentes.

Nesta perspectiva, cabem algumas considerações sobre as formas pelas quais o novo fator escasso (o capital natural) deve ser alocado e preservado. $\mathrm{Na}$ conceituação usual de economia, está implícita a ideia de que a alocação eficiente dos recursos é feita exclusivamente via mercados. A maioria dos componentes do capital natural, representada pelos serviços ecossistêmicos, apresenta características de não rivalidade e não exclusividade ${ }^{13}$, e a própria teoria econômica convencional

(13) Rivalidade refere-se a uma característica física de um bem cujo consumo por parte de um agente econômico reduz a quantidade disponível para consumo de outros agentes econômicos. Em outras palavras, um bem é rival quando é impossível seu consumo simultâneo e/ou quando o consumo de um agente econômico "desgasta" este mesmo bem, deixando quantidades menores para o consumo de outrem. Por seu turno, a característica de bens excludentes ou não excludentes refere-se a um atributo legal de um bem que previne o seu consumo simultâneo por parte de vários agentes, isto é, o conceito está relacionado com a definição de direitos de propriedade, permitindo que um agente restrinja o consumo de um bem cujo direito de propriedade lhe é atribuído. É interessante notar que existem várias combinações de serviços ecossistêmicos não rivais e rivais, bem como excludentes e não excludentes. Um exemplo seria o serviço ecossistêmico fundamental de capacidade de absorção de resíduos, rival no sentido de que seu uso por parte de um agente "reduz" sua quantidade para outro agente. 
reconhece que, para tais recursos, o livre mercado não é suficiente para operar sua eficiente alocação. Como afirmam Lipsey e Chrystal (2007, p. 282), "the obvious remedy in such cases is for the government to provide the good and pay for its provision out of general tax revenue".

Dada essa constatação, a alocação e preservação dos novos recursos escassos devem ser reavaliadas, já que o mercado, por si só, não promove alocação eficiente e não garante a sustentabilidade dos seus estoques. Este fato representa um desafio para as ciências econômicas, já que seus métodos de análise não previram uma nova configuração para a natureza da escassez de recursos e, por conseguinte, não oferecem respostas adequadas aos problemas colocados pela emergência do full world. É premente, portanto, o surgimento de um novo modelo de análise que incorpore explicitamente questões sobre alocação e preservação do capital natural.

\section{Full world economics e/ou green consensus: um novo modelo de desenvolvimento}

A mudança na natureza da escassez, isto é, a passagem de um mundo relativamente "vazio" (empty world), no qual o capital natural era superabundante e o capital produzido era o fator escasso, para um mundo "cheio" ( full world), no qual os artefatos humanos passam a ser o fator superabundante e o capital natural passa a ser o fator escasso, exige que se desenvolva um novo modelo de análise econômica que enfrente os problemas de alocação e preservação dentro do full world. Conforme Costanza (2008, p. 30), "ultimately we have to create a new vision of what the economy is and what it is for, and a new model of development that acknowledges the new full-world context".

As duas epígrafes colocadas na primeira página deste trabalho ilustram a necessidade de emergência deste novo modelo de análise. Se, de um lado, os métodos convencionais de análise econômica foram construídos no contexto do empty world, de outro, a emergência do full world exige que estes mesmos métodos sejam readequados no sentido de incorporar os novos desafios impostos pela nova natureza da escassez aqui discutida. Em última instância, é necessária a construção de uma nova visão de mundo que seja compatível com o full world. Este novo modelo pode ser referido como Full World Economics, como sugere Daly (2005), ou, ainda, como Green Consensus (Costanza, 2008).

A partir da problematização desenvolvida na seção anterior, deve ficar clara a necessidade de que este novo modelo persiga o objetivo precípuo de sustentabilidade econômica, social e ecológica ${ }^{14}$ através da preservação e alocação eficiente do capital natural, aumento sustentável do bem-estar humano e manutenção das condições de funcionamento adequado do ecossistema terrestre. Em outras palavras, este novo modelo deve reconhecer a importância da sustentabilidade ecológica e da eficiência

(14) Segundo Daly (2005), a principal ideia por trás do conceito de sustentabilidade é a mudança de trajetória do progresso a partir do crescimento não sustentável para o desenvolvimento que, presumivelmente, o é. 
econômica ${ }^{15}$ para o bem-estar humano, admitindo explicitamente a essencialidade do capital natural enquanto provedor de serviços fundamentais.

Em se tratando da sustentabilidade ecológica e preservação do capital natural é premente que o novo modelo incorpore a ideia de limites biofísicos ao crescimento contínuo do sistema econômico. Afora algumas correntes ainda marginais no pensamento econômico, as considerações sobre escala do sistema econômico e as consequências de um possível overshooting da capacidade de suporte do ecossistema global têm sido solenemente desconsideradas por parte dos partidários do vigente paradigma expansionista (neoclássico) (Rees, 2003).

Em contraste com o paradigma expansionista (parte "a" da Figura 1, abaixo), tem-se o paradigma ecológico-econômico (parte "b"), que vê a economia não como um elemento separado do meio ambiente, mas como um subsistema crescente, indissociavelmente integrado, completamente contido e integralmente dependente de um sistema maior não crescente (ecosfera ou biosfera). Tal paradigma demonstra uma relação termodinâmica entre sistema econômico e meio ambiente, sendo este último o produtor e o primeiro consumidor. Este requer fluxos contínuos de energia e insumos materiais provenientes da natureza que suportem a produção de bens e serviços (Rees, 2003).

É nítida a incompatibilidade entre o paradigma expansionista e o novo contexto de full world. Naquele, a expansão contínua do sistema econômico é obtida graças à substituibilidade entre capital natural e capital produzido pelo homem. Todavia, como mencionado, estes dois tipos de capital possuem um caráter de complementaridade entre si, o que invalida a tese de que a acumulação de capital produzido pelo homem superará a escassez de capital natural. Ao contrário, a crescente escassez de capital natural pode representar obstáculos à produção e acumulação dos demais tipos de capital. Ademais, a própria finitude da biosfera demonstra a inadequação deste paradigma dentro do novo padrão de escassez ${ }^{16}$.

Por outro lado, o paradigma econômico-ecológico explicitamente reconhece a existência dos limites biofísicos impostos pela biosfera. O subsistema econômico não deve ultrapassar um limite (threshold) além do qual pode haver uma ruptura do funcionamento adequado dos ecossistemas, levando a perdas potencialmente catastróficas e irreversíveis.

(15) Um dos princípios básicos da Economia Ecológica consiste em que o objetivo de sustentabilidade ecológica deve preceder o objetivo de eficiência econômica no sentido paretiano. No esquema analítico convencional, o sistema de preços é suficiente para definir a escala de uso ótimo dos recursos, que não necessariamente corresponde a uma escala ecologicamente sustentável. Para a Economia Ecológica, ao contrário, o sistema de preços deve ser influenciado por uma escala sustentável previamente definida com base no conhecimento disponível sobre a resiliência dos ecossistemas e em deliberações socialmente acordadas. A eficiência econômica dentro do modelo proposto é coerente com a visão econômico-ecológica.

(16) Em termos termodinâmicos, pode-se dizer que a biosfera é um sistema materialmente fechado (não troca matéria com seu meio externo), mas aberto ao fluxo contínuo de energia solar (Georgescu-Roegen, 1971). 
Embora não se tenha conhecimento sobre qual seria este limite, e considerando-se as incertezas sobre a dinâmica das funções ecológicas e a resiliência dos ecossistemas, o fato é que, certamente, um overshooting não seria inconsequente (Wackernagel; Silverstein, 2000). Sendo assim, um novo modelo de análise compatível com o full world deve considerar explicitamente a definição de escala ótima e sustentável do sistema econômico. Por escala ecologicamente sustentável, entende-se aquela em que o fluxo de throughput (transumo) ${ }^{17}$ está dentro da capacidade de suporte do sistema (carrying capacity). Por sua vez, escala ótima é aquela que maximiza a diferença entre os estoques de benefícios (wealth) e malefícios ( "illth") acumulados através do crescimento, isto é, iguala os benefícios marginais e os malefícios marginais do crescimento econômico (Daly, 1993). Segundo este mesmo autor, quando os malefícios do crescimento econômico ("illth") superam os seus benefícios ( "wealth") tem-se uma situação de crescimento "deseconômico" (Daly, 2003).

Figura 1

Paradigmas contrastantes: a visão expansionista (neoclássica) e a visão econômico-ecológica

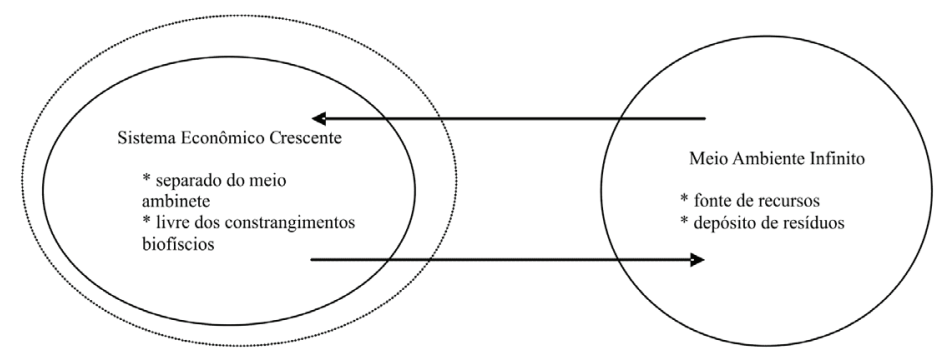

(a)

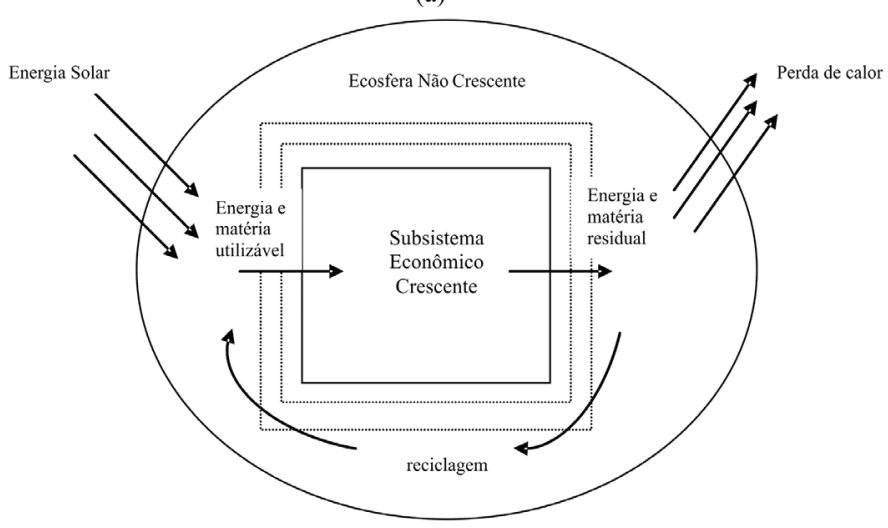

(b)

Fonte: Rees (2003, p. 34), com adaptações.

(17) Conforme Cavalcanti (2010), throughput, ou transumo, pode ser comparado ao fluxo metabólico de um organismo vivo que assimila recursos do meio externo (para sua sobrevivência/evolução) e os devolve na forma de rejeitos. 
Além de reconhecer explicitamente a necessidade de se manter o subsistema econômico dentro da capacidade de suporte dos ecossistemas, um modelo alternativo de desenvolvimento que seja consistente com o novo contexto de full world deve trazer alguns princípios sobre eficiência econômica ${ }^{18}$, direitos de propriedade, papel do governo etc. O Quadro 1, retirada de Costanza (2008), apresenta as principais diferenças entre o atual modelo de desenvolvimento (chamado de modelo baseado no Consenso de Washington) e um modelo alternativo de desenvolvimento (chamado de "Green Consensus").

Quadro 1

Um novo modelo de desenvolvimento

\begin{tabular}{|c|c|c|}
\hline & $\begin{array}{l}\text { Modelo atual de } \\
\text { desenvolvimento: o "Consenso de } \\
\text { Washington" }\end{array}$ & $\begin{array}{l}\text { Modelo sustentável de desenvolvimento: } \\
\text { um "Green Consensus" emergente }\end{array}$ \\
\hline Objetivo primário de politica & $\begin{array}{l}\text { Mais: crescimento econòmico no } \\
\text { sentindo convencional, medido } \\
\text { pelo PIB. A hipótess é que o } \\
\text { crescimento permitirá, em última } \\
\text { instância, a solução para todos os } \\
\text { outros problemas. Mais é sempre } \\
\text { melhor. }\end{array}$ & $\begin{array}{l}\text { Melhor: foco nas mudanças de } \\
\text { crescimento para o descnvolvimento, no } \\
\text { sentido de melhorias na qualidade de } \\
\text { vida, reconhecendo que o crescimento } \\
\text { possui subprodutos negativos. Mais nåo } \\
\text { é sempre melhor. }\end{array}$ \\
\hline Medida primária de progresso & PIB & GPI* (ou similar**) \\
\hline Escala/capacidade de suporte & $\begin{array}{l}\text { Nào se aplica, pois é assumido } \\
\text { que os mercados podem resolver } \\
\text { qualquer limitaçaso de recursos via } \\
\text { novas tocnologias e substitutos } \\
\text { para que os recursos estejam } \\
\text { scmpre disponiveis. }\end{array}$ & $\begin{array}{l}\text { Proocupação primária como um } \\
\text { determinante de sustentabilidade } \\
\text { ecológica. Capital natural e serviços } \\
\text { ecossistémicos nâo são infinitamente } \\
\text { substituívcis, e limites reais cxistem. }\end{array}$ \\
\hline Distribuiçăo/pobreza & $\begin{array}{l}\text { Há concordância, mas não há } \\
\text { açốes espccificas para cste tópico. } \\
\text { Crença no chamado efeito } \\
\text { "trickle-down". }\end{array}$ & $\begin{array}{l}\text { Preocupação primária desde que afete } \\
\text { dirctamente a qualidade de vida c o } \\
\text { capital social. De certa maneira, pode ser } \\
\text { exacerbada pelo crescimento. }\end{array}$ \\
\hline $\begin{array}{l}\text { Eficiència } \\
\text { econômica/alocação }\end{array}$ & $\begin{array}{l}\text { Preocupaçào primária, mas } \\
\text { geralmente incluindo apenas bens } \\
\text { e serviços transacionáveis no } \\
\text { mereado e instituições. }\end{array}$ & $\begin{array}{c}\text { Preocupação primária, mas incluindo os } \\
\text { bens e serviços nǒo transacionáveis nos } \\
\text { mercados tradicionais, alèm daqueles } \\
\text { transacionáveis. Enfatiza a necessidade } \\
\text { de incorporar o valor do capital natural e } \\
\text { social a fim de se alcançar uma } \\
\text { verdadeira eficiência alocativa } \\
\text { ****. }\end{array}$ \\
\hline Dircitos de propricdade & $\begin{array}{l}\text { Ênfase na propriedade privada e } \\
\text { mercados convencionais. }\end{array}$ & $\begin{array}{l}\text { Enfase no balanç de regimes de direitos } \\
\text { de propriedade apropriados à nutureza e } \\
\text { à escala do sistema juntamente com a } \\
\text { junçåo de dircitos c responsabilidades. } \\
\text { Papel maior das instituiçoōes de } \\
\text { propriedade comum em relação à } \\
\text { propricdade privada c estatal. }\end{array}$ \\
\hline Papel do governo & $\begin{array}{l}\text { Deve ser minimizado e } \\
\text { substituido, quando possivel, por } \\
\text { instituiçìes privadas e de } \\
\text { mercado. }\end{array}$ & $\begin{array}{l}\text { Papel central, incluindo novas funçōes, } \\
\text { como árbitro facilitador e "corretor" em } \\
\text { um novo conjunto de instituiçò̀es de } \\
\text { ativos comuns. }\end{array}$ \\
\hline Principios de governança & Capitalismo do laisses-faire. & $\begin{array}{l}\text { Princípios dc Lisboa }{ }^{* * * *} \text { para } \\
\text { govemança sustentável. }\end{array}$ \\
\hline
\end{tabular}

Fonte: Costanza (2008, p. 33).

Nota: * GPI $=$ Genuine Progress Indicator;

** Outros indicadores, que não o PIB, utilizados para medir não apenas o desenvolvimento econômico, mas também a qualidade ambiental e a qualidade de vida (por exemplo, o Environment Sustainability Index). Para uma discussão mais aprofundada sobre indicadores de sustentabilidade, ver Veiga (2010);

*** Aqui, a ideia de eficiência alocativa não difere essencialmente da eficiência paretiana. Há, contudo, o diferencial de que tal eficiência deve ser condicionada por tratamentos anteriores sobre sustentabilidade ecológica e justiça distributiva;

**** Sobre os Princípios de Lisboa, ver Costanza et al. (1998).

(18) Eficiência econômica no sentido paretiano, mas de acordo com princípios econômico-ecológicos (vide nota de rodapé número 15$)$. 
Entre os pontos levantados, são notórias as mudanças de orientação deste novo modelo no que se refere a aspectos de eficiência econômica e papel do governo. Quanto ao primeiro, considera-se que uma verdadeira eficiência alocativa apenas será alcançada a partir do momento em que todos os recursos que afetam o bemestar humano forem capturados pelos mercados e que seus mecanismos sejam diretamente influenciados pela definição prévia de uma escala ecológica sustentável. O problema é que os serviços ecossistêmicos, reconhecidamente tributários do bemestar humano (MEA, 2005), não são incluídos nas transações convencionais devido às suas características de bens públicos (não rivais e não excludentes).

Uma estratégia que um novo modelo consistente com o full world deve perseguir para alcançar uma verdadeira eficiência alocativa por meio da inclusão dos serviços ecossistêmicos nas transações de mercado é o constante aprimoramento dos esquemas valorativos do capital natural. Este é frequentemente valorado com base nas preferências individuais dos agentes econômicos sem levar em consideração aspectos de essencialidade ecológica e social.

Andrade (2010) advoga que o escopo da valoração econômica dos serviços ecossistêmicos pode ser ampliado através da chamada valoração dinâmico-integrada, na qual a característica principal é a modelagem econômico-ecológica dos sistemas naturais e econômicos, explicitamente considerando a dinâmica de mudanças dos valores dos serviços ecossistêmicos em função das interdependências entre as diferentes partes dos modelos e as suas diferentes escalas temporais e espaciais.

Quanto ao papel do governo, este deveria intermediar as transações entre os setores econômicos tradicionais e o chamado "setor dos comuns" (Barnes, 2006). Este último seria dedicado à preservação de ativos de propriedade comum, baseada em arranjos institucionais condizentes com a natureza dos recursos tratados e tendo como premissa básica a ideia de que todos os indivíduos, tanto da atual geração como das futuras, são coproprietários dos chamados "comuns", incluindo-se aí os componentes do capital natural. Além de intermediar as relações entre o "setor dos comuns" e os demais setores da economia, o governo também seria o responsável pela criação de condições favoráveis mínimas para a sua formação e regulação ${ }^{19}$.

Finalmente, considera-se que a full world economics deve se basear nos princípios fundamentais que norteiam o que Andrade e Romeiro (2011) definem como a "Economia dos Ecossistemas". Tais princípios são: (1) o capital natural impõe limites biofísicos à expansão (escala) da economia; (2) estes limites não são e não podem ser totalmente conhecidos, e seu overshooting pode levar a perdas irreversíveis potencialmente catastróficas; (3) a degradação do capital natural é um processo duplamente perverso, pois diminui o estoque de ativos naturais e compromete sua capacidade de geração de serviços; (4) dadas as incertezas envolvidas e a ignorância

(19) Ver, por exemplo, Barnes et al. (2008). 
sobre os processos que geram os serviços do capital natural, é recomendável uma postura de precaução cética; (5) direito de existência das espécies não humanas e (6) a verdadeira eficiência alocativa só será obtida a partir do momento em que todos os recursos que contribuem para o bem-estar humano forem incluídos adequadamente nas transações econômicas.

\section{À guisa de conclusão}

O objetivo central deste trabalho consiste em problematizar a questão da mudança na natureza da escassez de recursos representada pela mudança entre um empty world para um full world no qual o capital natural é o recurso escasso e limitante do desenvolvimento econômico, bem como apontar para as implicações que este fato encerra para as ciências econômicas em termos de enfoque de políticas econômicas. Argumentou-se sobre a necessidade de emergência de um novo modelo de análise que incorpore estratégias diretamente voltadas ao enfrentamento da nova natureza da escassez dos recursos, comprometido com a preservação e alocação eficiente dos mesmos, provenientes do capital natural.

A contribuição das reflexões realizadas é a de enfatizar a importância de considerar o capital natural como essencial ao suporte à vida humana, no sentido de que, através das relações existentes entres seus componentes, são gerados os chamados serviços ecossistêmicos. Aliado a isso, a aproximação da escala do sistema econômico aos limites biofísicos revela um fenômeno de "nova escassez", que questiona a pertinência da estrutura analítica e metodológica das ciências econômicas, além do próprio conceito de sustentabilidade até então implícito nas análises convencionais.

A trajetória da sociedade capitalista e da engrenagem econômica por ela ensejada tem sido apontada como ecologicamente insustentável no sentido de que os sinais de degradação do capital natural e a deterioração de seus fluxos de serviços tornam-se cada vez mais claros. Entre outros, pode-se citar a recorrência de desastres ecológicos, as mudanças no clima e a contínua perda de diversidade biológica representada pela homogeneização de paisagens naturais e pela escalada da perda irrecuperável de espécies e de seus habitats.

A ocorrência da mais recente crise econômica representa, em última instância, a inadequação de um modelo socioeconômico-ecológico construído sobre as premissas do capitalismo de livre mercado e do crescimento econômico ilimitado incapaz de promover o bem-estar sustentável da sociedade humana e garantir os mesmos padrões para as gerações futuras. Em opinião publicada no jornal The New York Times, em março de 2009, Thomas Friedman questiona: "what if the crisis of 2008 represents something much more fundamental than a deep recession? What if it's telling us that the whole growth model we created over the last 50 years is 
simply unsustainable economically and ecologically and that 2008 was when we hit the wall — when Mother Nature and the market both said: 'no more'?" (Friedman, 2009).

Este trabalho partiu da premissa de que é preciso reavaliar a natureza da escassez dos recursos e o potencial das ferramentas econômicas tradicionais para atingir simultaneamente os objetivos de alocação eficiente e preservação. Se, de um lado, a Economia é a ciência que se preocupa com a alocação dos recursos escassos, de outro, é preciso perguntar quais são estes recursos escassos, quais são suas características, bem como quais são os meios para alcançar sua alocação. Em última instância, é preciso também levar em consideração questões de preservação destes recursos.

A partir das ideias de empty world e full world, mostrou-se a emergência de uma "nova escassez" representada pela escala crescente do sistema econômico e pelo reconhecimento da função de provedor de serviços essenciais à vida exercida pelo capital natural. Seguindo-se a lógica econômica de que se deve maximizar a produtividade do fator mais escasso e aumentar a sua oferta, cumpre-se estimular o desenho de políticas econômicas voltadas a incrementar a produtividade do capital natural e os benefícios dele derivados. Em outras palavras, o novo contexto do full world exige que sejam consideradas questões como a alocação eficientemente dos recursos provenientes do capital natural, bem como a necessidade de preservá-los.

O paradigma expansionista (ou neoclássico) é incompatível com o novo contexto de full world. Não há infinita substituibilidade entre capital natural e capital produzido pelo homem e, portanto, possibilidade de expansão contínua do (sub) sistema econômico. É preciso, pois, que se tenha um novo modelo de análise que reconheça os limites biofísicos ao crescimento econômico, a essencialidade do capital natural e a profunda dependência humana sobre os seus serviços. A visão pré-analítica de que a economia é um subsistema de um sistema maior que o suporta, que é materialmente fechado (embora aberto ao fluxo entrante de energia solar) e finito, coaduna-se com o novo contexto de full world, pois admite a necessidade de definição da escala ótima do sistema econômico. É neste sentido que se afirma que uma visão econômico-ecológica é mais adequada à nova natureza da escassez e deve ser dominante dentro de uma nova full world economics.

Como fator escasso, o capital natural encerra algumas especificidades que justificam um tratamento especial da teoria econômica no que tange à sua alocação e preservação. Em primeiro lugar, os componentes do capital natural são, em sua maioria, não rivais e não excludentes, o que os coloca dentro da categoria de bens públicos. Em segundo lugar, as complexas e dinâmicas relações entre seus componentes geram um fluxo de serviços de suporte às atividades humanas que, na prática, são de difícil ou impossível substituição. A partir dessa discussão, argumenta- 
se que a consideração das complexidades inerentes aos processos ecológicos traz à tona novos elementos para a análise da escassez e contribui para tratamentos menos reducionistas das relações entre meio natural e sistema econômico.

Em se tratando de sua alocação, o atributo de bem público de grande parte do capital natural faz com que este não seja considerado nas transações econômicas e que sua contribuição para o bem-estar humano não seja corretamente avaliada. $\mathrm{O}$ fato de não ser precificado como outro bem ou serviço faz com que não haja incentivos para sua preservação, levando à sua superexploração e, muitas vezes, à sua perda total. Resta, pois, encontrar meios eficazes para se incluir adequadamente o capital natural nas transações de mercado de maneira a se obter uma verdadeira eficiência alocativa.

Não se trata, porém, de reduzir o problema ambiental a questões de falhas de mercado, já que este novo modelo de desenvolvimento admite que nem todos os serviços do capital natural podem ser precificados, o que inviabiliza a tese de que a solução dos problemas ambientais se daria ao se incorporar os custos ambientais das atividades econômicas. Ademais, o novo modelo aqui tratado pressupõe que o processo de alocação de recursos do capital natural seja precedido pela definição de uma escala ecológica sustentável que não pode ser determinada pelo sistema de preços, tal como nas análises convencionais.

Assim sendo, há maior destaque para a importância da política ambiental, que deve ser robusta o suficiente e amparada num processo de valoração amplo e refinado, que capte não só a dimensão econômica dos serviços ecossistêmicos, mas também suas dimensões ecológica e social de modo que se possa garantir que a alocação do capital natural seja compatível com sua preservação e suas peculiaridades. Ao mesmo tempo, aspectos de governança social participativa e institucionalidade apropriada devem ser considerados, pois somente a geração de incentivos econômicos pode não ser suficiente para estimular os agentes a preservar o capital natural, já que os benefícios daí decorrentes manifestam-se em diferentes escalas espaciais e temporais.

Quanto à sua preservação, é preciso reconhecer, ainda, que a degradação do capital natural é um processo duplamente perverso, pois diminui o estoque de ativos naturais e compromete sua capacidade de geração de serviços úteis para o bem-estar humano. Neste ponto, uma preocupação sobre o agravamento da "nova escassez" é o fato de que, recentemente, uma massa que representa grande parte da população mundial está rapidamente ascendendo a um padrão de consumo similar ao dos países desenvolvidos. A pujança do crescimento econômico de países como China, Índia e Brasil, principalmente, pode ser vista como benéfica do ponto de vista de que uma parcela crescente de suas populações tem acesso a um nível maior de afluência material. Todavia, os padrões sobre os quais repousam seus processos 
de crescimento ainda estão enquadrados numa visão de empty world e não refletem preocupações com a natureza dos novos recursos escassos.

Por fim, há que se admitir que a emergência de um novo modelo de análise no qual o crescimento econômico não seja visto como o objetivo final da sociedade exigirá mudanças mais amplas no modo de organização da sociedade humana. Há quem diga que a nova full world economics é uma "impossibilidade política" dada a aderência ao crescimento econômico e à contínua expansão do consumo. Todavia, como afirma Daly (2005), entre uma "impossibilidade política" e uma "impossibilidade biofísica", representada pelos limites reais ao crescimento econômico, é preferível que se enfrente a primeira. Se a continuidade de um modelo de crescimento econômico que ignora a crescente escassez de recursos, tais como a capacidade de absorção de resíduos, coloca em risco a sustentabilidade das atividades humanas, é prudente que, mesmo num cenário em que tal risco seja ainda pequeno, sejam repensados os meios usuais através dos quais são perseguidos aumentos de bem-estar. A emergência da "nova escassez" indica que políticas econômicas não devem mais focar unicamente a eficiência econômica, mas o tripé sustentabilidade ecológica, equidade social (inter e intrageracional) e eficiência econômica.

\section{Referências bibliográficas}

ANDRADE, D. C. Modelagem e valoração de serviços ecossistêmicos: uma contribuição da economia ecológica. 2010. Tese (Doutorado)-Instituto de Economia, Unicamp, 2010. 268p.

; ROMEIRO, A. R. Degradação ambiental e teoria econômica: algumas reflexões sobre uma "economia dos ecossistemas". Economia, Brasília, v. 12, p. 3-26, 2011.

. Serviços ecossistêmicos e sua importância para o sistema econômico Discussão, n. 155).

ARNT, R. (Org.). O que os economistas pensam sobre sustentabilidade. São Paulo: Editora $34,2010$.

ARROW, K.; BOLIN, B.; COSTANZA, R.; DASGUPTA, P.; FOLKE, C.; HOLLING, C. S.; JANSSON, B. O.; LEVIN, S.; MÄLER, K. G.; PERRINGS, C.; PIMENTEL, D. Economic growth, carrying capacity, and the environment. Science, 268, p. 520-521, 1995.

BARNES, P. Capitalism 3.0: a guide to reclaiming the commons. San Francisco: BerrettKoehler, 2006.

; COSTANZA, R.; HAWKEN, P.; ORR, D.; OSTRON, E.; UMAÑA, A.; YOUNG,

O. Creating an atmospheric trust. Science 319 (5864), p. 724, Feb. 2008.

BARNETT, H. Scarcity and growth revisited. In: SMITH, V. K. Scarcity and growth reconsidered. Baltimore: Johns Hopkins University Press for Resources for the Future, 1979. 
BARNETT, H.; MORSE, C. Scarcity and growth: the economics of natural resource availability. Baltimore: Johns Hopkins University Press for Resources for the Future, 1963.

BEDDOE, R.; COSTANZA, R.; FARLEY, J.; GARZA, E.; KENT, J.; KUBISZEWSKI, I.; MARTINEZ, L.; MCCOWEN, T.; MURPHY, K.; MYERS, N.; OGDEN, Z.; STAPLETON, K.; WOODWARD, J. Overcoming systemic roadblocks to sustainability: the evolutionary redesign of worldviews, institutions, and technologies. Proceeding of National Academy of Sciences (PNAS), v. 106, n. 8, p. 2483-2489, 2009.

BERKES, F.; FOLKE, C. Investing in cultural capital for sustainable use of natural capital. In: JANSSON, A. M.; HAMMER, M.; FOLKE, C.; COSTANZA, R. (Ed.). Investing in natural capital: the ecological economics approach to sustainability. Washington, DC: Island Press, 1994. p. 22-37.

BOULDING, K. E. The economics of the coming spaceship earth. In: JARRETT, H. (Ed.). Environmental quality in a growing economy. Baltimore: John Hopkins University Press, 1966.

CAVALCANTI, C. Concepções da economia ecológica: suas relações com a economia dominante e a economia ambiental. Estudos Avançados, v. 24, n. 68, p. 53-67, 2010.

CBD. Convention on Biological Diversity. Concluded at Rio de Janeiro - 5 June 1992. Disponível em: $<$ http://www.cbd.int/doc/legal/cbd-un-en.pdf> $>$. Acesso em: jun. 2009.

COSTANZA, R. Toward a new sustainable economy. Real-World Economics Review, n. 49, p. 20-21, $12^{\text {th }}$ Mar. 2009.

. Stewardship for a "full” world. Current History, 107, p. 30-35, Jan. 2008.

p. 4-10, 2000.

Social goals and the valuation of ecosystem services. Ecosystems, v. 3, n. 1,

; FISHER, B.; ALI, S.; BEER, C.; BOND, L.; BOUMANS, R.; DANIGELIS, N. L.; DICKINSON, J.; ELLIOT, C.; FARLEY. J.; GAYER, D. E.; GLENN, M.; HUDSPETH, T. R.; MAHONEY, D. F.; MC CAHILL, L.; MCINTOSH, B.; REED, B.; RIZVI, S. A. T.; RIZZO, D. M.; SIMPATICO, T.; SNAPP, R. An integrative approach to quality of life measurement, research and policy. Surveys and Perspectives Integrating Environment \&. Society (Sapiens), v. 1, n. 1, p. 11-15, 2008.

; DALY, H. E.; FOLKE, C.; HAWKEN, P.; HOLLING, C. S.; MCMICHAEL, A. J.; PIMENTEL, D.; RAPPORT, D. Managing our environmental portfolio. BioScience, v. 50, n. 2, p. 149-155, 2000.

; ANDRADE, F.; ANTUNES, P.; VAN DEN BELT, M.; BOERSMA, D.; BOESCH, D. F.; CATARINO, F.; HANNA, S.; LIMBURG, K.; LOW, B.; MOLITOR, M.; PEREIRA, J. G.; RAYNER, S.; SANTOS, R.; WILSON, J.; YOUNG, M. Principles for sustainable governance of the oceans. Science, v. 281, n. 5374, p. 198-199, 1998.

; DALY, H. E. Natural Capital and Sustainable Development. Conservation Biology, v. 6, n. 1, p. 37-46, 1992. 
DAILY, G. Nature's services: societal dependence on natural ecosystem. Washington, DC: Island Press, 1997.

DALY, H. E. Economics in a full world. Scientific American, p. 100-107, Sept. 2005.

. Uneconomic growth in a full world. Social Contract Journal, v. 13, n. 3, p. 171$180,2003$. Press, 1996.

Beyond growth. The economics of sustainable development. Boston: Beacon

Ecological economics: the concept of scale and its relation to allocation, distribution and uneconomic growth. School of Public Affairs, University of Maryland, 1993. (Discussion Paper).

; FARLEY, J. Ecological economics: principles and applications. Washington, DC: Island Press, 2004.

EASTERLIN, R. Explaining happiness. Proceeding of National Academy of Sciences (PNAS), v. 100, n. 19, p. 11176-11183, 2003.

FRIEDMAN, T. The inflection is near? The New York Times (Opinion), Mar. $7^{\text {th }}, 2009$. Disponível em: <http://www.nytimes.com/2009/03/08/opinion/08friedman.html? r $\mathrm{r}=1>$. Acesso em: maio 2009.

GEORGESCU-ROEGEN, N. The entropy law and the economic process. Cambridge: Harvard University Press, 1971.

GILlESPIE, A. Foundations of economics. New York: Oxford University Press, 2007.

HARDIN, G. The tragedy of the commons. Science, v. 162, n. 3859, p. 1243-1248, 1968.

JACKSON, T. Beyond the growth economy. Journal of Industrial Ecology, v. 13, n. 4, p. 487-490, 2009a.

2009b.

. Prosperity without growth: economics for a finite planet. London: Earthscan,

JORGENSEN, S .E. Integration of ecosystem theories: a pattern. Dordrecht (The Netherlands): Kluwer Academic Publishers, 1992.

KRAUTKRAEMER, J. A. Economics of natural resources scarcity: the state of the debate. Resources for the Future, Discussion Paper, 05-14, 2005.

LEVIN, S. A. Ecosystems and the biosphere as complex adaptive systems. Ecosystems, 1, p. 431-436, 1998.

LIPSEY, R. G.; CHRYSTAL, K. A. Economics. New York: Oxford University Press, 2007.

MCNEILL, J. R. Something new under the sun: an environmental history of the twentiethcentury world. New York: Norton, 2000.

MEADOWS, D. H.; MEADOWS, D. L.; RANDERS, J.; BEHRENS III, W. Limits to growth. New York: Universe Books, 1972. 
MEA (MILLENNIUM ECOSYSTEM ASSESSMENT). Ecosystem and human well-being: Synthesis. Washington DC: Island Press, 2005.

Ecosystem and human well-being: a framework for assessment. Washington, DC: Island Press, 2003.

NAEEM, S., CHAPIN III, F. S.; COSTANZA, R.; EHRLICH, P. R.; GOLLEY, F. B.; HOOPER, D. U.; LAWTON, J. H.; O’NEILL, R. V.; MOONEY, H. A.; SALA, O. E.; SYMSTAD, A. J.; TILMAN, D. Biodiversity and ecosystem functioning: maintaining natural life support processes. Washington, D.C.: Ecological Society of America, 1999. (Issues in Ecology, n. 4).

NEW SCIENTIST. The folly of growth: how to stop the economy killing the planet. Special Issue, Oct, 2008.

NORDHAUS, W. D. Resources as a constraint on growth. The American Economic Review, v. 64, n. 2 , p. $22-26,1974$.

REES, W. E. Economic development and environmental protection: an ecological economics perspective. Environmental Monitoring and Assessment, v. 86, n. 1-2, p. 29-45, 2003.

ROCKSTRÖM, J.; STEFFEN, W.; NOONE, K.; PERSSON, A.; CHAPIN, F. S.; LAMBIN, E. R.; LENTON, T. M.; SCHEFFER, M.; FOLKE, C.;. SHELLNHUBER, H. J.; NYKVIST, B.; WIT, C. A. de; HUGHES, T.; VAN DER LEEUW, S.; RODHE, H.; SÖRLIN, S.; SNYDER, P. K.; COSTANZA, R.; SVEDIN, U.; FALKENMARK, M.; KARLBERG, L.; CORELL, R. W.; FABRY, V. J.; HANSEN, J.; WALKER, B.; LIVERMAN, D.; RICHARDSON, K.; CRUTZEN, P.; FOLEY, J. A safe operating space for humanity. Nature, 461, p. 472-475. 2009a.

et al. Planetary boundaries: exploring the safe operating space for humanity. Ecology and Society, v. 14, n. 2, p. 32-49, 2009b.

ROMEIRO, A. R. Cultural and institutional constraints on ecological learning under uncertainty. Campinas: Instituto de Economia - Unicamp, ago. 2002. (Texto para Discussão, n. 110).

SIMON, J. The state of humanity: steadily improving. Cato Policy Report, v. 17, n. 5, 1995. Disponível em: <http://www.cato.org/pubs/policy_report/pr-so-js.html $>$. Acesso: maio 2009.

SIMPSON, R. D.; TOMAN, M. A.; AYRES, R. U. Scarcity and growth in the new millennium: summary. Resources for the Future, Discussion Paper 04-01, 2004.

SOLOW, R. M. The economics of resources or the resources of economics. The American Economic Review, v. 64, n. 2, p. 1-14, 1974.

STEFFEN, W.; CRUTZEN, P. J.; MCNEILL, J. R. The anthropocene: are humans now overwhelming the great forces of nature? Ambio, v. 36, n. 8, p. 614-620, 2007.

SUKHDEV, P. The economics of ecosystems and biodiversity. Interim Report of the Convention on Biological Diversity. European Communities, Cambridge: United Kingdom, 2008. 
STOLL, S. The fear of fallowing: the specter of a no-growth world. Harper's Magazine, p. 88-94, Mar. 2008.

TILMAN, D.; POLASKY, S. Ecosystem goods and services in their limits: the role of biological diversity and management practices. In: SIMPSON, R. D.; TOMAN, M. A.; AYRES, R. U. Scarcity and growth revisited: natural resources and the environmental in the new millennium. Washington DC: Resources for the Future, 2005.

UCS. World Scientists' Warning to Humanity. Union of Concerned Scientists' statement,

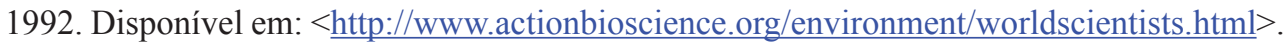
Acesso: maio 2009.

VEIGA, J. E. Indicadores de sustentabilidade. Estudos Avançados, v. 24, n. 68, p. 39-52, 2010.

VICTOR, P. Managing without growth: slower by design, not disaster. Cheltenham: Edward Elgar Publishing, 2008.

VITOUSEK, P. M.; MOONEY, H. A.; LUBCHENCO, J.; MELliLO, J. M. Human domination on earth's ecosystems. Science, 277, p. 494-499, 1997.

WACKERNAGEL, M.; SILVERSTEIN, J. Big things first: focusing on the scale imperative with the ecological footprint. Ecological Economics, v. 32, n. 3, p. 391-394, 2000.

WOODWARD, D.; SIMMS. A. Growth isn 't working: the unbalanced distribution of benefits and costs from economic growth. London, UK: New Economics Foundation, 2006. 26p. 